\title{
Impact of reduced renal function on prognosis in Japanese patients with coronary artery disease: a prospective cohort of Shinken Database 2007
}

\author{
Michinari Nakamura, Takeshi Yamashita, Junji Yajima, Yuji Oikawa, Ken Ogasawara, Hajime Kirigaya, \\ Koichi Sagara, Akira Koike, Hitoshi Sawada and Tadanori Aizawa
}

Patients with coronary artery disease (CAD) frequently have impaired renal function, but the prevalence and influence of renal dysfunction on their prognosis in Japan remain uncertain. With a prospective study comprising all the new patients who had visited our hospital between 2004 and $2007(n=6562)$, we investigated the prevalence of renal dysfunction and its influence on the prognosis of CAD patients. The glomerular filtration rate (GFR) was calculated by using the GFR equation used for the Japanese population. Of those, 797 patients with CAD and blood tests available were analyzed (median follow-up periods of 693 days). Patients were further classified into four subgroups according to estimated GFR value (eGFR): normal (90 $\leqslant$ eGFR, $12.2 \%$ ), mildly impaired ( $60 \leqslant$ eGFR $<90,58.3 \%$ ), moderately impaired ( $30 \leqslant$ eGFR $<60,23.6 \%$ ) and severely impaired renal function (eGFR $<30,5.9 \%$ ). The 2 -year survival and cardiovascular event (cardiac death, nonfatal myocardial infarction or readmission for heart failure)-free rates were significantly different among the four subgroups: $98.9,97.7,89.3$ vs.

$67.8 \%$, respectively $(P<0.001$ for trend), and $100,98.8,89.0$ vs. $70.0 \%$, respectively $(P<0.001$ for trend). The age- and gender-adjusted mortality increased significantly in moderately impaired (hazard ratio (HR) $3.1,95 \%$ confidence interval (Cl) 1.383-7.017) and in severely impaired subgroups (HR 10.1,95\% $\mathrm{Cl} 4.244-24.178$ ) compared with those with eGFR of 60 or more. After adjustment for baseline differences, eGFR was independently associated with death and cardiovascular events (HR 0.983 and $0.981,95 \% \mathrm{Cl} 0.968-0.998$ and $0.965-0.998$, respectively). In conclusion, our study identified the prevalence and association of eGFR with prognosis in Japanese patients with CAD, suggesting that strict care for not only CAD but also renal dysfunction is needed for further prevention of cardiovascular events.

Hypertension Research (2009) 32, 920-926; doi:10.1038/hr.2009.114; published online 21 August 2009

Keywords: atherosclerosis; chronic kidney disease; coronary artery disease; estimated glomerular filtration rate; prognosis

\section{INTRODUCTION}

Coronary artery disease (CAD) is becoming more common in the elderly as the mean age of the population increases in Japan. ${ }^{1}$ Patients with $\mathrm{CAD}$ have been believed to have more frequently impaired renal function, and more reduced renal function may result in worse clinical outcomes after revascularization for CADs. ${ }^{2-6}$ In addition, not only have racial and geographic differences been reported to exist with regard to the prevalence of chronic kidney disease and clinical outcomes after revascularization, but also procedural differences in revascularization between countries may affect clinical outcomes after revascularization. ${ }^{7,8}$ In real medical practice, physicians should always consider renal dysfunction in patients with preexisting or suspected $\mathrm{CAD}$ as a significant predictor. Although the prevalence of an estimated glomerular filtration rate (eGFR) in the general Japanese population, ${ }^{9-11}$ patients with heart failure ${ }^{12}$ or patients with sleep-related breathing disorder ${ }^{13}$ has been reported earlier, the prevalence of chronic kidney disease and long-term prognosis in
Japanese patients with CAD based on the eGFR value are less well identified.

A prospective cohort study, the Shinken Database, was designed to investigate the mortality and morbidity of Japanese patients with cardiovascular diseases. ${ }^{14}$ In this study with this database, we evaluated the distribution of an eGFR value and long-term prognosis in Japanese patients with CAD according to the eGFR value.

\section{METHODS}

Study population

We have conducted a prospective cohort study named the 'Shinken Database' since 2004 to assess the clinical variables, mortality and morbidity of Japanese patients with cardiovascular diseases. ${ }^{14}$ The study population comprised all the new patients who had visited our hospital, the Cardiovascular Institute, in Tokyo, between June 2004 and March 2007 and did not meet the exclusion criteria, including patients who already had confirmed diagnosis of cancer and had plans to receive treatments for it at the initial visits, patients living abroad, 
and patients visiting just one time without any examinations. Among the database population, all patients diagnosed as CAD and receiving blood tests at the initial visits were identified. The Cardiovascular Institute is a teaching hospital with a cardiac catheterization laboratory and a cardiac surgery facility.

When written informed consent for entering the Shinken database was obtained from the patient, all data were transmitted to the Shinken database center at the hospital, and all their clinical outcomes were monitored by medical recordings, mail and/or telephone contact with the patients. The Ethical Committee in the Cardiovascular Institute granted ethical permission for this study.

\section{Definitions}

Coronary artery disease encompasses silent myocardial ischemia, stable angina pectoris, unstable angina, acute myocardial infarction and vasospastic angina. Acute coronary syndrome was composed of unstable angina and acute myocardial infarction. An eGFR was calculated by using the GFR equation used for the Japanese population; ${ }^{15,16}$ GFR $=194 \times($ serum creatinine $)^{-1.094} \times(\text { age })^{-0.287} \times(0.739$ if female $)$. Chronic kidney disease was defined as a baseline eGFR $<60 \mathrm{~m} \mathrm{~min}^{-1}$ per $1.73 \mathrm{~m}^{2} .{ }^{17}$ Angiographic significant stenosis was defined as $\geqslant 50 \%$ stenosis. Target lesion revascularization (TLR) was defined as percutaneous coronary intervention (PCI) for a treated lesion during the index procedure or coronary artery bypass graft surgery (CABG) after the index procedure.

This study included information on baseline characteristics of patients and their cardiac history, risk factors, the first therapeutic strategies (PCI, CABG or medical without invasive strategies) for $\mathrm{CAD}$ and medications at baseline.

\section{Outcomes}

We evaluated the prevalence of an eGFR and relationship between the eGFR and number of diseased coronary arteries. The following clinical outcomes were also investigated: all-cause death, the cardiovascular events composed of cardiac death, nonfatal myocardial infarction or readmission for heart failure, and TLR among patients undergoing PCI.

\section{Statistical analysis}

Categorical variables were compared using $\chi^{2}$-test. Results for continuous data were expressed as mean \pm s.d. Analysis of variance was performed to compare distributed variables. Cumulative event curves were plotted by the Kaplan-Meier method stratified according to the eGFR, and the difference was tested by log-rank test. Pearson's correlation coefficient was used to test the association between the number of diseased coronary arteries and the eGFR. The association between the baseline characteristics and the outcomes was assessed using the Cox proportional hazards model by a stepwise procedure. Covariates of presentation (presence or absence of acute coronary syndrome), age, gender, presence or absence of diabetes mellitus, statin use, number of diseased coronary arteries, ejection fraction, congestive heart failure on admission and the eGFR value were used to construct a multivariate Cox proportional hazards survival model by a stepwise procedure. Similarly, covariates of presentation (presence or absence of acute coronary syndrome), age, gender, congestive heart failure on admission, statin use, aspirin use, number of diseased coronary arteries, ejection fraction value and the eGFR value were used to construct a multivariate Cox proportional hazards cardiovascular event-free rates model by a stepwise procedure. Analyses of data were performed using statistical software (SPSS version 14.0; SPSS Japan, Tokyo, Japan). All $P$-values were two-sided, and significance was defined as $P<0.05$ for all analyses.

\section{RESULTS}

\section{Patient population}

Six thousand five hundred and sixty-two patients were enrolled in the Shinken Database 2004-2007 and followed up. Of the total, 822 patients were diagnosed as $\mathrm{CAD}$, but 25 patients did not receive blood tests at the initial visits. Therefore, the other 797 patients were identified in this study. The median follow-up period was 693 days. Patients were further classified into four subgroups according to the
eGFR value using the GFR cutoffs from the National Kidney Foundation: 97 patients $(12.2 \%)$ had normal renal function $\left(90 \mathrm{ml} \mathrm{min}^{-1}\right.$ per $\left.1.73 \mathrm{~m}^{2} \leqslant \mathrm{eGFR}\right) ; 465$ patients $(58.3 \%)$ had mildly impaired renal function $\left(60 \mathrm{ml} \mathrm{min}^{-1}\right.$ per $1.73 \mathrm{~m}^{2} \leqslant \mathrm{eGFR}$ and eGFR $<90 \mathrm{ml} \mathrm{min}^{-1}$ per $\left.1.73 \mathrm{~m}^{2}\right) ; 188$ patients $(23.6 \%)$ had moderately impaired renal function $\left(30 \mathrm{ml} \mathrm{min}^{-1}\right.$ per $1.73 \mathrm{~m}^{2} \leqslant \mathrm{eGFR}$ and eGFR $<60 \mathrm{ml} \mathrm{min}^{-1}$ per $1.73 \mathrm{~m}^{2}$ ) (chronic kidney disease stage 3$) ;{ }^{18}$ and 47 patients $(5.9 \%)$ had severely impaired renal function $\left(\mathrm{eGFR}<30 \mathrm{ml} \mathrm{min}^{-1}\right.$ per $1.73 \mathrm{~m}^{2}$ ) (chronic kidney disease stages 4 and 5 ). ${ }^{18}$ Figure 1 shows the prevalence of the eGFR in all patients enrolled in the Shinken Database 2004-2007 $(n=6562)$ and in patients with CAD $(n=797)$ among the database, suggesting that patients with CAD had worse renal function compared with all patients visiting our hospital. The prevalence of chronic kidney disease in patients with $\mathrm{CAD}$, in patients with acute coronary syndrome and in all patients was 29.5, 31.6 and 19.9\%, respectively $(P<0.001)$.

\section{Baseline characteristics}

Baseline characteristics at the initial visits are shown in Table 1. The mean eGFR was $68.0 \pm 22.2 \mathrm{ml} \mathrm{min}^{-1}$ per $1.73 \mathrm{~m}^{2}$. The rates of earlier myocardial infarction and earlier CABG increased with declining eGFR. Patients with decreasing eGFRs had a lower ejection fraction and larger number of diseased coronary arteries. An eGFR correlated negatively and significantly with the number of diseased coronary arteries $(r=-0.256, P<0.001)$. Acute coronary syndrome presented at the initial visit was observed at similar rates among the four subgroups. However, the proportions of congestive heart failure at baseline increased with declining eGFR value. Patients in the lowest category of eGFR had the highest rate of diabetes mellitus. Although a lower eGFR was associated with increasing age, this variable was used in the determination of eGFR.

\section{Therapeutic strategies and medications}

The proportion of patients undergoing PCI or medical treatment without invasive procedures was similar among the four subgroups, but CABG was more frequently performed in patients with decreasing eGFR (Table 2). Medications at baseline were similar among the four subgroups except statin and diuretics. Patients with a lower eGFR more often received diuretics but less often statin.

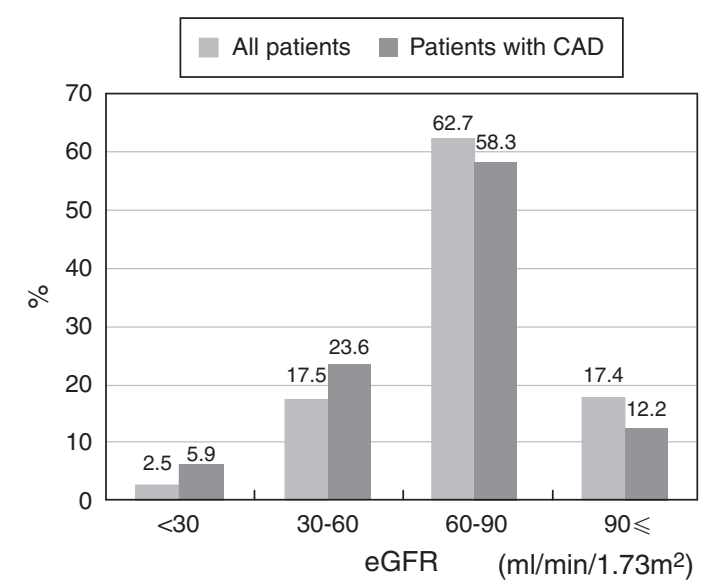

Figure 1 Prevalence of estimated glomerular filtration rate (GFR) at baseline. Patients with coronary artery disease (CAD) $(n=797)$ had worse renal function compared with all patients visiting our hospital $(n=6562)$. The prevalence of chronic kidney disease in patients with CAD and in all patients visiting the hospital was 29.5 and $19.9 \%$, respectively $(P<0.001)$. 


\begin{tabular}{|c|c|c|c|c|c|c|}
\hline & \multirow[b]{2}{*}{ Total $(\mathrm{n}=797)$} & \multicolumn{4}{|c|}{ eGFR } & \multirow[b]{2}{*}{ P for trenc } \\
\hline & & $<30(n=47)$ & $30-60(n=188)$ & $60-90(n=465)$ & $90 \leqslant(n=97)$ & \\
\hline Age, years & $64.8 \pm 11.6$ & $70.8 \pm 11.4$ & $71.1 \pm 10.7$ & $63.5 \pm 10.1$ & $55.7 \pm 11.7$ & $<0.001$ \\
\hline Body mass index, $\mathrm{kg} \mathrm{m}^{-2}$ & $24.0 \pm 3.33$ & $22.2 \pm 3.93$ & $23.6 \pm 3.32$ & $24.3 \pm 3.08$ & $24.3 \pm 3.84$ & $<0.001$ \\
\hline eGFR, $\mathrm{ml} \mathrm{min}^{-1}$ per $1.73 \mathrm{~m}^{2}$ & $68.0 \pm 22.2$ & $12.9 \pm 9.11$ & $50.2 \pm 7.66$ & $73.7 \pm 8.42$ & $102.0 \pm 12.9$ & $<0.001$ \\
\hline \multicolumn{7}{|l|}{ History of CAD } \\
\hline Earlier MI, $n(\%)$ & $214(26.9)$ & $18(38.3)$ & $73(38.8)$ & $105(22.6)$ & $18(18.6)$ & $<0.001$ \\
\hline Earlier CABG, $n(\%)$ & $44(5.5)$ & $9(19.1)$ & $14(7.4)$ & $20(4.3)$ & $1(1.0)$ & $<0.001$ \\
\hline Earlier PCI, $n(\%)$ & $140(17.6)$ & $8(17.0)$ & $41(21.8)$ & $76(16.3)$ & $15(15.5)$ & 0.373 \\
\hline \multicolumn{7}{|l|}{ Presentation } \\
\hline \multicolumn{7}{|l|}{ Comorbidity } \\
\hline Dyslipidemia, $n(\%)$ & $475(59.6)$ & $13(27.7)$ & $108(57.4)$ & $297(63.9)$ & $57(58.8)$ & $<0.001$ \\
\hline Hyperuricemia, $n(\%)$ & $106(13.3)$ & $8(17.0)$ & $44(23.4)$ & $43(9.2)$ & $11(11.3)$ & $<0.001$ \\
\hline Diabetes mellitus, $n(\%)$ & $255(32.0)$ & $25(53.2)$ & $60(32.1)$ & 139 (29.9) & $31(32.0)$ & 0.014 \\
\hline Cigarette smoker, $n(\%)$ & $451(56.6)$ & $24(51.1)$ & $93(49.7)$ & $271(58.4)$ & $63(64.9)$ & 0.056 \\
\hline Heart failure, $n(\%)$ & $106(13.3)$ & $22(46.8)$ & 37 (19.7) & $40(8.6)$ & $7(7.2)$ & $<0.001$ \\
\hline Ejection fraction, \% & $61.0 \pm 13.5$ & $49.6 \pm 17.0$ & $58.1 \pm 15.7$ & $63.1 \pm 11.8$ & $61.9 \pm 11.5$ & $<0.001$ \\
\hline
\end{tabular}

Abbreviations: ACS, acute coronary syndrome; CABG, coronary artery bypass graft surgery; CAD, coronary artery disease; eGFR, estimated glomerular filtration rate; MI, myocardial infarction; PCl, percutaneous coronary intervention.

Table 2 Therapeutic strategy and medications

\begin{tabular}{|c|c|c|c|c|c|c|}
\hline & Total $(\mathrm{n}=797)$ & $<30(\mathrm{n}=47)$ & $30-60(n=188)$ & $60-90(n=465)$ & $90 \leqslant(n=97)$ & P for trend \\
\hline $\mathrm{PCl}, n(\%)$ & $426(53.5)$ & $24(51.1)$ & $93(49.5)$ & $254(54.6)$ & $55(56.7)$ & 0.578 \\
\hline Use of DES, $n(\%)$ & $217(27.3)$ & $11(23.4)$ & $48(25.5)$ & $135(29.1)$ & $23(23.7)$ & 0.564 \\
\hline CABG, $n(\%)$ & $90(11.3)$ & 5 (10.6) & $36(19.1)$ & $42(9.0)$ & 7 (7.2) & 0.001 \\
\hline \multicolumn{7}{|l|}{ Medication } \\
\hline ACE inhibitor, $n(\%)$ & $116(14.6)$ & 5 (10.9) & $33(17.9)$ & $67(14.8)$ & $11(11.6)$ & 0.431 \\
\hline ARB, $n(\%)$ & $227(28.5)$ & $13(28.3)$ & $60(32.6)$ & $127(28.0)$ & $27(28.4)$ & 0.710 \\
\hline$\beta$-blocker, $n(\%)$ & $282(35.4)$ & $16(34.8)$ & $71(38.6)$ & $162(35.8)$ & $33(34.7)$ & 0.892 \\
\hline Statin, $n(\%)$ & $346(43.4)$ & $11(23.9)$ & $83(45.1)$ & $208(46.0)$ & $44(46.3)$ & 0.037 \\
\hline Ca channel blocker, $n(\%)$ & $350(43.9)$ & $15(32.6)$ & $78(42.4)$ & $210(46.4)$ & $47(49.5)$ & 0.215 \\
\hline Diuretics, $n(\%)$ & $160(20.1)$ & $16(34.0)$ & $69(36.7)$ & $64(13.8)$ & $11(11.3)$ & $<0.001$ \\
\hline
\end{tabular}

Abbreviations: ACE inhibitor, angiotensin-converting enzyme inhibitor; ARB, angiotensin receptor blocker; DES, drug-eluting stents.

\section{Clinical outcomes}

During the median follow-up periods of 693 days, all-cause death, cardiovascular events (cardiac death, nonfatal myocardial infarction or readmission for heart failure) and TLR occurred in 45,45 and 101 patients, respectively. The 2-year survival rates in patients with CAD were 98.9, 97.7, 89.3 and $67.8 \%$, respectively $(P<0.001$ for trend) (Figure 2a), and the 2-year cardiovascular event (cardiac death, nonfatal myocardial infarction or readmission for heart failure)-free rates were also significantly different among the four subgroups: 100, 98.8, 89.0 and 70.0\%, respectively $(P<0.001$ for trend; Figure $2 \mathrm{~b})$. 
a

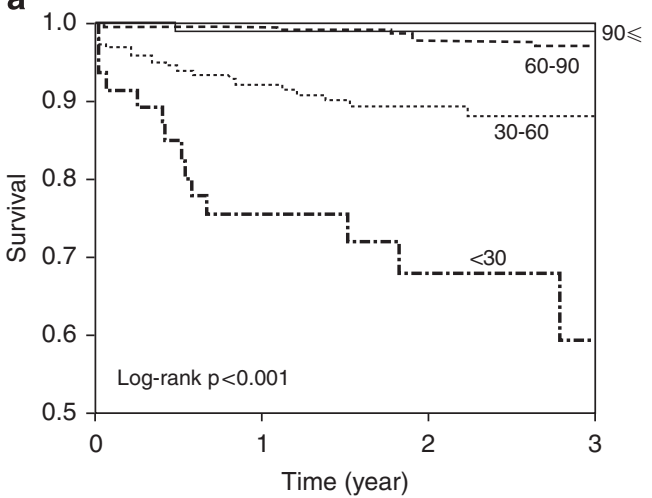

b

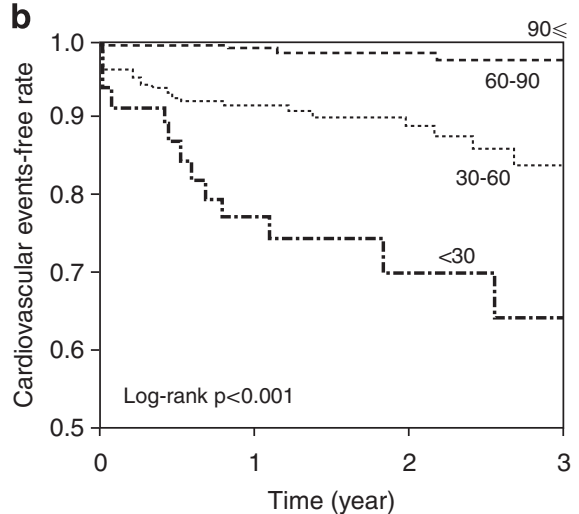

No. at Risk

$\begin{array}{lcccc}90 \leqslant & 97 & 82 & 45 & 23 \\ 60-90 & 465 & 389 & 226 & 94 \\ 30-60 & 188 & 143 & 77 & 26 \\ <30 & 47 & 30 & 15 & 5\end{array}$

Figure 2 Kaplan-Meier survival curves (a) and cardiovascular event-free curves (b) according to the estimated glomerular filtration rate (GFR) value. Both survival and event-free rates were significantly different among the four subgroups (both $P<0.001$ ). Cardiovascular events were composed of cardiac death, nonfatal myocardial infarction or readmission for heart failure.

In the group of patients undergoing PCI as a first-line treatment for CAD $(n=426)$, the overall survival rates, cardiovascular event-free rates and readmission for heart failure-free rates were significantly different among the four subgroups (Figures $3 \mathrm{a}, 3 \mathrm{~b}$ and $3 \mathrm{c}$ ); however, unexpectedly, the incidences of TLR were similar regardless of the difference of the eGFR value (Figure $3 \mathrm{~d}$ ).

The age- and gender-adjusted incidences of all-cause death and cardiovascular events increased significantly in subgroups with eGFR of $30-59 \mathrm{ml} \mathrm{min}^{-1}$ per $1.37 \mathrm{~m}^{2}$ (hazard ratio (HR) 3.1 and $4.8,95 \%$ confidence interval (CI) $1.383-7.017$ and 2.043-11.453, $P=0.006$ and $P<0.001$, respectively) and in those with eGFR $<30 \mathrm{ml} \mathrm{min}^{-1}$ per $1.37 \mathrm{~m}^{2}$ (HR 10.1 and $13.5,95 \%$ CI $4.244-24.178$ and 5.345-34.326, $P<0.001$ and $P<0.001$, respectively) compared with those without chronic kidney disease.

Even after adjustment for confounding covariates, an eGFR was independently associated with mortality and cardiovascular events (HR 0.983 and $0.981,95 \%$ CI $0.968-0.998$ and $0.965-0.998, P=0.029$ and 0.025 , respectively). These findings also persisted among patients undergoing PCI even after adjustment (HR 0.974, 95\% CI 0.955$0.922, P=0.005$ for mortality, and HR $0.967,95 \%$ CI $0.947-0.987$, $P=0.002$ for cardiovascular events).

\section{DISCUSSION}

This study is a prospective cohort, identifying the prevalence of the eGFR in patients with CAD and also revealing that impaired renal function was a significant independent risk factor for all-cause death and cardiovascular events composed of cardiac death, nonfatal myocardial infarction or readmission for heart failure in these patients. These findings also persisted in patients undergoing PCI as a first-line treatment for CAD. Although there has been limited information showing the prevalence of chronic kidney disease and prognosis in Japanese patients with $\mathrm{CAD}$, this study identified the prevalence and prognosis in such a population.

\section{Prevalence of chronic kidney disease}

Coresh et al. ${ }^{8}$ reported that the prevalence of chronic kidney disease was $13 \%$ in the United States. Wen et al. ${ }^{19}$ identified that the frequency of chronic kidney disease was $11.9 \%$ in Taiwan. Reports from Japan showed that $7-19 \%$ of adults have chronic kidney disease. ${ }^{9-11,18,20}$ In addition, among Japanese patients with chronic heart failure or sleep-related breathing disorder, the prevalence of chronic kidney disease was reported to be 26.7 or $30.5 \%$, respectively. ${ }^{12,13}$ In this study, the prevalence of chronic kidney disease in all patients visiting our hospital $(n=6562)$, in patients with CAD $(n=797)$ or in patients with acute coronary syndrome $(n=291)$ was $19.9,29.5$ and $31.6 \%$, respectively. Compared with the prevalence of chronic kidney disease in Western countries, the prevalence seems to be higher in Japan, and the frequency of chronic kidney disease in patients with preexisting cardiovascular disease or CAD was higher in this study compared with that in the general Japanese population reported earlier. These differences are partially explained by racial difference and by an increase in other risk factors for chronic kidney disease, including glucose intolerance, dyslipidemia and obesity in Japan., ${ }^{1,6}$ Anavekar et $a .^{21}$ reported that the prevalence of chronic kidney disease in patients suffering from acute myocardial infarction in Western countries was $33.5 \%$, consistent with the results of this study (31.6\% of acute coronary syndrome). Although the prevalence of the eGFR in Japanese patients with CAD had not been well identified, this study showed the prevalence of chronic kidney disease in the groups.

In this study, the rate of acute coronary syndrome on initial arrival was high (approximately 40\%) among patients with CAD, and heart failure was also observed in $47 \%$ of patients with severely impaired renal function. One of the probable reasons for these high proportions was that some of the patients were transferred to our hospital for further investigation and treatment because of severe cardiac complication. Therefore, we notify that the present findings could be obtained on these important backgrounds, and it is possible that this specific background somewhat influenced the prognosis.

\section{Clinical outcomes}

Weiner et al. ${ }^{22}$ reported that the presence of chronic kidney disease in patients with preexisting cardiovascular disease was associated with an increased risk for recurrent cardiovascular disease outcomes even after adjustment for baseline differences. Cardarelli et al. ${ }^{23}$ showed that among chronic kidney patients (eGFR $<60 \mathrm{ml} \mathrm{min}^{-1}$ per $1.73 \mathrm{~m}^{2}$ ), the 

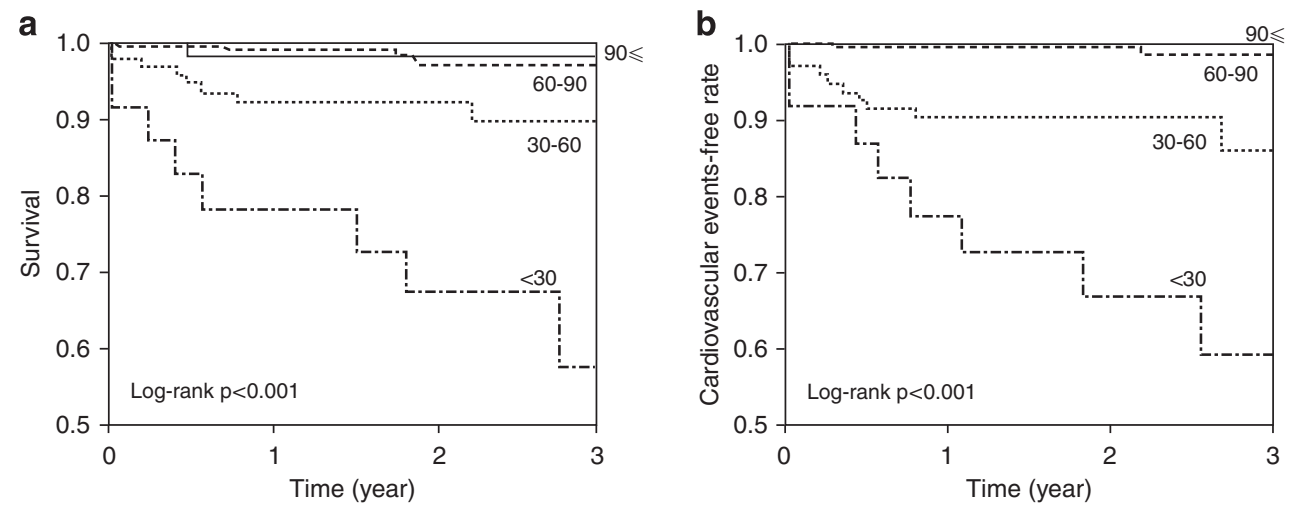

$\begin{array}{lcccc}\text { No. at Risk } & & & & \\ 90 \leqslant & 55 & 51 & 31 & 15 \\ 60-90 & 254 & 222 & 137 & 63 \\ 30-60 & 93 & 76 & 44 & 16 \\ <30 & 24 & 17 & 10 & 6\end{array}$
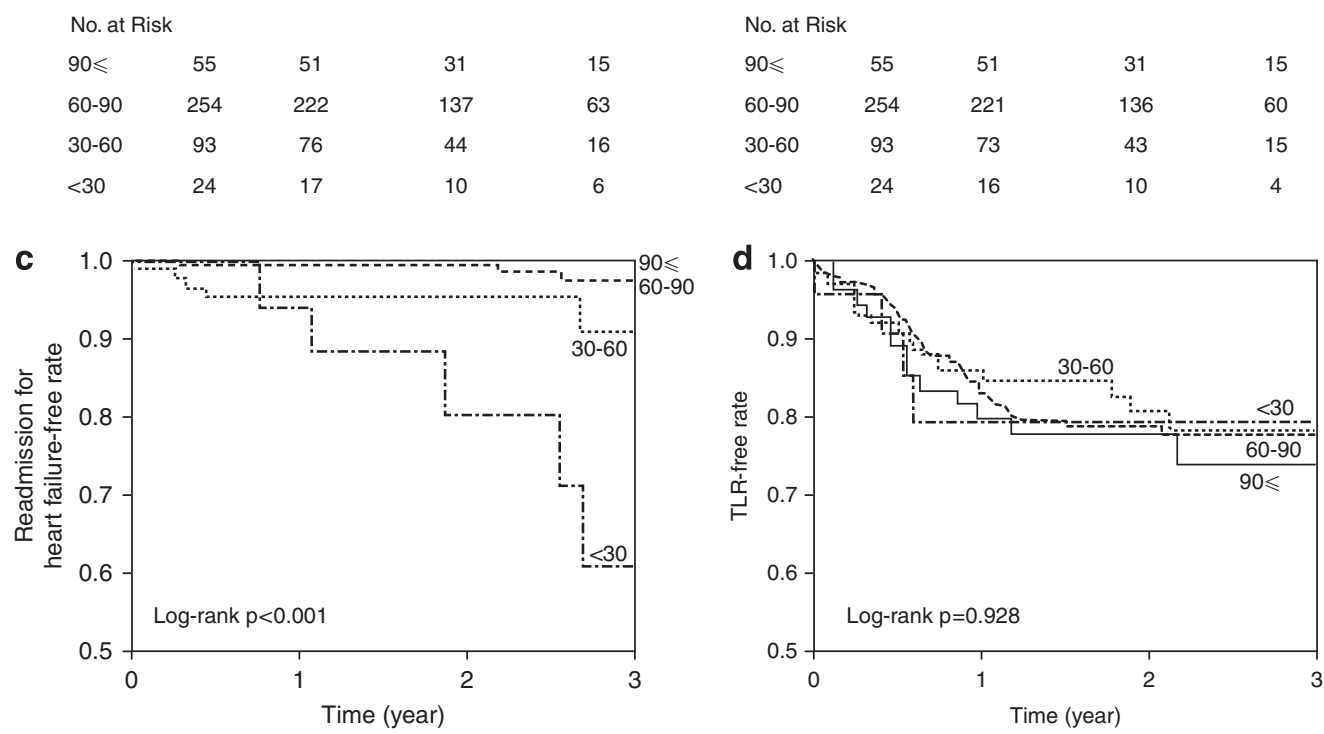

$\begin{array}{lcccc}\text { No. at Risk } & & & & \\ 90 \leqslant & 55 & 51 & 31 & 15 \\ 60-90 & 254 & 221 & 136 & 60 \\ 30-60 & 93 & 75 & 43 & 15 \\ <30 & 24 & 16 & 10 & 4\end{array}$

$\begin{array}{lcccc}\text { No. at Risk } & & & & \\ 90 \leqslant & 55 & 41 & 25 & 10 \\ 60-90 & 254 & 185 & 105 & 44 \\ 30-60 & 93 & 67 & 36 & 12 \\ <30 & 24 & 13 & 8 & 3\end{array}$

Figure 3 Kaplan-Meier survival curves (a), cardiovascular event-free curves (b), readmission for heart failure-free curves (c) and target lesion revascularization (TLR)-free curves (d) among patients undergoing percutaneous coronary intervention ( $n=426$ ) according to the estimated glomerular filtration rate (GFR) value. Cardiovascular events were composed of cardiac death, nonfatal myocardial infarction or readmission for heart failure.

1-year all-cause mortality and major adverse cardiac event (myocardial infarction, revascularization and death) after PCI were 13.3 and $31.3 \%$, respectively. According to the APPROACH database, ${ }^{24}$ the adjusted 8-year survival rates after PCI for CAD in the reference group (serum creatinine $<2.3 \mathrm{mg}$ per $100 \mathrm{ml}$ ), non-dialysis kidney disease (serum creatinine $>2.3 \mathrm{mg}$ per $100 \mathrm{ml}$ but not on dialysis) group and dialysis group were $80.4,32.7$ and $41.2 \%$, respectively. When we assess the clinical outcome of patients with $\mathrm{CAD}$, we should also consider the differences in the therapeutic strategy and medications because the frequency and procedure of revascularization for CAD are different between the Western countries and Japan. This study identified the 2-year survival rates according to the eGFR value among the Japanese population with CAD: $98.9 \%$ in $90 \mathrm{ml} \mathrm{min}^{-1}$ per $1.37 \mathrm{~m}^{2} \leqslant \mathrm{eGFR}$, $97.7 \%$ in eGFR of $60-89 \mathrm{ml} \mathrm{min}^{-1}$ per $1.37 \mathrm{~m}^{2}, 89.3 \%$ in eGFR of $30-59 \mathrm{ml} \mathrm{min}^{-1}$ per $1.37 \mathrm{~m}^{2}$ and $67.8 \%$ in eGFR less than $30 \mathrm{ml} \mathrm{min}^{-1}$ per $1.37 \mathrm{~m}^{2}$. Furthermore, the age- and gender-adjusted incidences of all-cause death and cardiovascular events increased significantly in the moderately renal dysfunction subgroups (HR 3.1 and 4.8, respectively) and the severely renal dysfunction subgroups (HR 10.1 and 13.5, respectively) compared with those without chronic kidney disease. Therefore, this study revealed that the difference in survival rate even among patients with chronic kidney disease was found to be strong and significant. In addition, an eGFR value was an independent predictor for all-cause death and cardiovascular events. Although most of the risk of chronic kidney disease is due to its association with other predictors for CAD, our results clearly showed that the presence of chronic kidney disease remained an independent risk factor for the clinical outcome of CAD.

Mechanisms by which impaired renal function increases the risk of cardiovascular events are under investigation. Earlier reports showed that a lower eGFR was associated with an increased number of diseased vessels, ${ }^{25-27}$ which was consistent with this study. Patients with chronic kidney disease have been believed to have elevated inflammation markers, leading to a state of accelerated atherosclerosis, which may partially cause worse clinical outcomes as an eGFR became lower. ${ }^{25,28-30}$ Other explanations may be conditions associated with 
accelerated atherosclerosis and endothelial dysfunction such as oxidative stress, anemia and fluid overload in chronic kidney disease.

In the United States Renal Data System database, the 2-year allcause survival in dialysis patients was $56.4 \%$ after CABG, $48.2 \%$ after percutaneous transluminal coronary angioplasty and $48.4 \%$ after stent implantation for CAD. ${ }^{31}$ In contrast, the 2-year survival rate of dialysis patients was $79.6 \%$ in Japan, ${ }^{32}$ and in this study, the 2-year survival rate of patients with the eGFR less than $30 \mathrm{ml} \mathrm{min}^{-1}$ per $1.73 \mathrm{~m}^{2}$ was $67.8 \%$. We did not classify the group of severely impaired renal function into two groups: group with severely impaired renal function without dialysis and group on dialysis. Therefore, we cannot strictly compare each result, but the survival rate of our study patients appears to be lower than that in Japanese dialysis patients. One of the probable reasons may be the preexisting comorbidities of CAD in the present study patients.

Repeat revascularization is a significant cardiovascular event because restenosis is not always a benign clinical event. ${ }^{33}$ However, some earlier reports indicated that there was no difference in the repeat revascularization rate between the chronic kidney disease group and the normal renal function group. ${ }^{34,35}$ In this study, the rates of TLR were also similar among the four subgroups despite the reduced renal function. There are some probable explanations. First, patients with severely impaired renal function may have frequently fatal events before developing restenosis because the 2-year survival rate in the subgroup was lower than $70 \%$. Second, it is possible that physicians hesitated to perform a coronary angiography and intervention repeatedly because of renal dysfunction in the moderately and severely impaired renal function groups.

\section{Limitations}

There are several limitations in this study. First, we could not evaluate the role of contrast-induced nephropathy after performing coronary angiography and intervention procedure. However, the differences in clinical outcomes according to the eGFR value at baseline persisted even after adjustment. Second, the patients in this study were the population visiting our hospital specializing in cardiovascular disease, which might be potentially biased by the characteristics of the hospital and study patients. However, we believe that it is important to show the prevalence of the eGFR, contemporary treatment and clinical outcomes of the population with CAD in a specialized hospital in Japan. Third, although proteinuria seems to be a significant risk factor for developing chronic kidney disease, ${ }^{36,37}$ in our hospital urinalysis for proteinuria had not been performed routinely and therefore chronic kidney disease stages 1 and 2 (the eGFR $\geqslant 60 \mathrm{ml} \mathrm{min}^{-1}$ per $1.73 \mathrm{~m}^{2}$ and proven renal dysfunction ${ }^{18}$ ) were not identified. Accordingly, more studies should be required for assessing the differences in prognosis among patients with eGFR $\geqslant 90 \mathrm{ml} \mathrm{min}^{-1}$ per $1.73 \mathrm{~m}^{2}$ and the presence of proteinuria or its absence. Fourth, although patients had many comorbidities, as shown in Table 1, and the underlying etiology of renal dysfunction also varied from diabetic nephropathy to hypertensive kidney disease, it was difficult to identify the cause of chronic kidney disease in many cases. However, we believe that it is important that the prognosis for patients with CAD was significantly different according to the eGFR value on initial arrival regardless of the various underlying etiologies. Finally, information on medications during follow-up was not assessed. Nonetheless, we believe that the findings of our study represent precise prevalence and prognosis, as we performed this study using a highly accurate method for diagnosing and following all cardiovascular events.

In conclusion, this study revealed that the incidence of chronic kidney disease in patients with $\mathrm{CAD}$ was approximately as high as
$30 \%$ and that the risk of all-cause death or cardiovascular events composed of cardiac death, nonfatal myocardial infarction or readmission for heart failure increased significantly with declining eGFR. Even after adjustments for baseline differences and therapies, renal dysfunction was a significant independent risk factor for all-cause mortality and cardiovascular events in this population. In addition to treatment for $\mathrm{CAD}$, appropriate consideration and strict care for chronic kidney disease is needed for further prevention of cardiovascular events in Japanese patients.

\section{ACKNOWLEDGEMENTS}

We thank Drs Kazuyuki Nagashima, Tokuhisa Uejima, Takayuki Ohtsuka, Ryuichi Funada and Shunsuke Matsuno of the Cardiovascular Institute and Dr Shinya Suzuki of the University of Tokyo Hospital for their collection of data. We also thank all study participants, physicians, co-medical staff, and co-workers.

1 Kubo M, Kiyohara Y, Kato I, Tanizaki Y, Arima H, Tanaka K, Nakamura H, Okubo K, lida $M$. Trends in the incidence, mortality, and survival rate of cardiovascular disease in a Japanese community: the Hisayama study. Stroke 2003; 34: 2349-2354.

2 Tonelli M, Jose P, Curhan G, Sacks F, Braunwald E, Pfeffer M, Cholesterol and Recurrent Events (CARE) Trial Investigators. Proteinuria, impaired kidney function, and adverse outcomes in people with coronary disease: analysis of a previously conducted randomised trial. Br Med J 2006; 332: 1426

3 Wison S, Foo K, Cunningham J, Cooper J, Deaner A, Knight C, Ranjadayalan K, Timmis AD. Renal function and risk stratification in acute coronary syndromes. Am J Cardiol 2003; 91: 1051-1054.

4 Reinecke H, Trey T, Matzkies F, Fobker M, Breithardt G, Schaefer RM. Grade of chronic renal failure, and acute and long-term outcome after percutaneous coronary interventions. Kidney Int 2003; 63: 696-701.

5 Inaguma D, Tatematsu M, Shinjo H, Suzuki S, Mishima T, Inaba S, Kurata K, Yuzawa Y, Matsuo S. Relationship between renal function at the time of percutaneous coronary intervention and prognosis in ischemic heart disease patients. Clin Exp Nephrol 2007; 11: 56-60.

6 Sarnak MJ, Levey AS, Schoolwerth AC, Coresh J, Culleton B, Hamm LL, McCullough PA, Kasiske BL, Kelepouris E, Klag MJ, Parfrey P, Pfeffer M, Raij L, Spinosa DJ, Wilson PW, American Heart Association Councils on Kidney in Cardiovascular Disease, High Blood Pressure Research, Clinical Cardiology, and Epidemiology and Prevention. Kidney disease as a risk factor for development of cardiovascular disease: a statement from the American Heart Association Councils on Kidney in Cardiovascular Disease, High Blood Pressure Research, Clinical Cardiology, and Epidemiology and Prevention. Circulation 2003; 108: 2154-2169.

7 Iseki K, Horio M, Imai E, Matsuo S, Yamagata K. Geographic difference in the prevalence of chronic kidney disease among Japanese screened subjects: Ibaraki versus Okinawa. Clin Exp Nephrol 2009; 13: 44-49.

8 Coresh J, Selvin E, Stevens LA, Manzi J, Kusek JW, Eggers P, Van Lente F, Levey AS. Prevalence of chronic kidney disease in the United States. JAMA 2007; 298: 2038-2047.

9 Imai E, Horio M, Iseki K, Yamagata K, Watanabe T, Hara S, Ura N, Kiyohara Y, Hirakata H, Moriyama T, Ando Y, Nitta K, Inaguma D, Narita I, Iso H, Wakai K, Yasuda Y, Tsukamoto $\mathrm{Y}$, Ito S, Makino H, Hishida A, Matsuo S. Prevalence of chronic kidney disease (CKD) in the Japanese general population predicted by the MDRD equation modified by a Japanese coefficient. Clin Exp Nephrol 2007; 11: 156-163.

10 Nakamura K, Okamura T, Hayakawa T, Kadowaki T, Kita Y, Ohnishi H, Saitoh S, Sakata K, Okayama A, Ueshima H, The NIPPON DATA90 Research Group. Chronic kidney disease is a risk factor for cardiovascular death in a community-based population in Japan: NIPPON DATA90. Circ J 2006; 70: 954-959.

11 Ninomiya T, Kiyohara Y, Tokuda Y, Doi Y, Arima H, Harada A, Ohashi Y, Ueshima H, Japan Arteriosclerosis Longitudinal Study Group. Impact of kidney disease and blood pressure on the development of cardiovascular disease: an overview from the Japan Arteriosclerosis Longitudinal Study. Circulation 2008; 118: 2694-2701.

12 Shiba N, Matsuki M, Takahashi J, Tada T, Watanabe J, Shimokawa H. Prognostic importance of chronic kidney disease in Japanese patients with chronic heart failure. Circ J 2008; 72: 173-178.

13 Iseki K, Tohyama K, Matsumoto T, Nakamura H. High Prevalence of chronic kidney disease among patients with sleep related breathing disorder (SRBD). Hypertens Res 2008; 31: 249-255.

14 Suzuki S, Yamashita T, Ohtsuka T, Sagara K, Uejima T, Oikawa Y, Yajima J, Koike A, Nagashima K, Kirigaya H, Ogasawara K, Sawada H, Aizawa T. Prevalence and prognosis of patients with atrial fibrillation in Japan: a prospective cohort of Shinken Database 2004. Circ J 2008; 72: 914-920.

15 Japanese Society of Nephrology \& The Japanese Society of Hypertension. CKD Practical Guide (Hypertension). Tokyoigakusha, 2008, pp 20. (Japanese).

16 Matsuo S, Imai E, Horio Y, Yasuda Y, Tomita K, Nitta K, Yamagata K, Tomino Y, Yokoyama $\mathrm{H}$, Hishida $\mathrm{A}$, On behalf of the collaboraters for developing Japanese 
equation for estimating GFR. Revised equations for estimated GFR from serum creatinine in Japan. Am J Kidney Dis 2009; 53: 982-992.

17 National Kidney Foundation. Kidney Disease Outcome Quality Initiative (K/DOQI) clinical practice guidelines for chronic kidney disease: evaluation, classification, and stratification. Am J Kidney Dis 2002; 39(suppl 1): S1-S266.

18 Japanese Society of Nephrology. Evidence-Based Practice Guideline for the Treatment of CKD 2009. Tokyoigakusha, 2009, p17 (Japanese).

19 Wen CP, Cheng TY, Tsai MK, Chang YC, Chan HT, Tsai SP, Chiang PH, Hsu CC, Sung PK, Hsu YH, Wen SF. All-cause mortality attributable to chronic kidney disease: a prospective cohort study based on 462293 adults in Taiwan. Lancet 2008; 371: 2173-2182.

20 Iseki K, Kohagura K, Sakima A, Iseki C, Kinjo K, Ikemiya Y, Takishita S. Changes in the demographics and prevalence of chronic kidney disease in Okinawa, Japan (1993 to 2003). Hypertens Res 2007; 30: 55-62.

21 Anavekar NS, McMurray JJ, Velazquez EJ, Solomon SD, Kober L, Rouleau JL, White HD, Nordlander R, Maggioni A, Dickstein K, Zelenkofske S, Leimberger JD, Califf RM, Pfeffer MA. Relation between renal dysfunction and cardiovascular outcomes after myocardial infarction. N Engl J Med 2004; 351: 1285-1295.

22 Weiner DE, Tighiouart H, Stark PC, Amin MG, MacLeod B, Griffith JL, Salem DN, Levey AS, Sarnak MJ. Kidney disease as a risk factor for recurrent cardiovascular disease and mortality. Am J Kidney Dis 2004; 44: 198-206.

23 Cardarelli F, Bellasi A, Veledar E, Vaccarino V, Raggi P. Impact of race and chronic kidney disease on 1-year outcome in patients undergoing percutaneous coronary interventions: a single tertiary center experience. Am Heart J 2008; 155: 1027-1032.

24 Hemmelgarn BR, Southern D, Culleton BF, Mitchell LB, Knudtson ML, Ghali WA, Alberta Provincial Project for Outcomes Assessment in Coronary Heart Disease (APPROACH) Investigators. Survival after coronary revascularization among patients with kidney disease. Circulation 2004; 110: 1890-1895.

25 Fathi RB, Gurm HS, Chew DP, Gupta R, Bhatt DL, Ellis SG. The interaction of vascular inflammation and chronic kidney disease for the prediction of long-term death after percutaneous coronary intervention. Am Heart J 2005; 150: 1190-1197.

26 Bonello L, De Labriolle A, Roy P, Steinberg DH, Okabe T, Pinto Slottow TL, Xue Z, Torguson R, Suddath WO, Satler LF, Kent KM, Pichard AD, Lindsay J, Waksman R. Impact of optimal medical therapy and revascularization on outcome of patients with chronic kidney disease and on dialysis who presented with acute coronary syndrome. Am J Cardiol 2008; 102: 535-540.

27 Blackman DJ, Pinto R, Ross JR, Seidelin PH, Ing D, Jackevicius C, Mackie K, Chan C, Dzavik V. Impact of renal insufficiency on outcome after contemporary percutaneous coronary intervention. Am Heart J 2006; 151: 146-152.

28 Muntner P, Hamm LL, Kusek JW, Chen J, Whelton PK, He J. The prevalence of nontraditional risk factors for coronary heart disease in patients with chronic kidney disease. Ann Intern Med 2004; 140: 9-17.

29 Arici M, Walls J. End-stage renal disease, atherosclerosis, and cardiovascular mortality: is C-reactive protein the missing link? Kidney Int 2001; 59: 407-414.

30 Jungers P, Massy ZA, Nguyen Khoa T, Fumeron C, Labrunie M, Lacour B, DescampsLatscha B, Man NK. Incidence and risk factors of atherosclerotic cardiovascular accidents in predialysis chronic renal failure patients: a prospective study. Nephrol Dial Transplant 1997; 12: 2597-2602.

31 Herzog CA, Ma JZ, Collins AJ. Comparative survival of dialysis patients in the United States after coronary angioplasty, coronary artery stenting, and coronary artery bypass surgery and impact of diabetes. Circulation 2002; 106: 2207-2211.

32 Japanese Society of Dialysis Therapy. An overview of regular dialysis treatment in Japan as of Dec 31, 2006. 2007. http://docs.jsdt.or.jp/overview/ (accessed 25 February 2009).

33 Chen MS, John JM, Chew DP, Lee DS, Ellis SG, Bhatt DL. Bare metal stent restenosis is not a benign clinical entity. Am Heart J 2006; 151: 1260-1264.

34 Papafaklis MI, Naka KK, Papamichael ND, Kolios G, Sioros L, Sclerou V, Katsouras CS, Michalis LK. The impact of renal function on the long-term clinical course of patients who underwent percutaneous coronary intervention. Catheter Cardiovasc Interv 2007; 69: 189-197.

35 Mishkel GJ, Varghese JJ, Moore AL, Aguirre F, Markwell SJ, Shelton M. Short- and longterm clinical outcomes of coronary drug-eluting stent recipients presenting with chronic renal disease. J Invasive Cardiol 2007; 19: 331-337.

36 Imai E, Horio M, Yamagata K, Iseki K, Hara S, Ura N, Kiyohara Y, Makino H, Hishida A, Matsuo S. Slower decline of glomerular filtration rate in the Japanese general population: a longitudinal 10-year follow-up study. Hypertens Res 2008; 31: 433-441.

37 Iseki K, Iseki C, Ikemiya Y, Kinjo K, Takishita S. Risk of developing low glomerular filtration rate or elevated serum creatinine in a screened cohort in Okinawa, Japan. Hypertens Res 2007; 30: 167-174. 